\title{
Implementation of ecological audit in the enterprises activities for the benefit of the environment
}

\author{
Elena Vasilyeva $^{1, *}$ and Angela Mottaeva ${ }^{1,2}$ \\ ${ }^{1}$ Moscow State University of Civil Engineering, 26, Yaroslavskoe Shosse, 129337, Moscow, Russia \\ ${ }^{2}$ Moscow Region State University, Radio str, 10A, 105005, Moscow, Russia
}

\begin{abstract}
The author believes that the problems connected with the impact on the environment are very relevant, including the matters of the assessment of damage caused to it and the matters of the assessment of risk from this damage for the users of nature, as well as for the state institutes, which are carrying out control, for private and public organizations. The current situation in Russia is characterized by the need of introduction of new ecologic-and-economic concepts, such as ecological audit and revision of the role and value of old economic tools in the state policy. The scheme of ecological audit, its main directions in Russia at the level of the enterprise, regions and the country in general as well as within the international cooperation are considered in the article. At the same time, some problems connected with legislation shortcomings exist. Besides, the author emphasizes the inadmissibility to solve the environmental problems at the expense of detriment of economic interests, the need of balanced and reasonable decisions.
\end{abstract}

\section{Introduction}

Ecological audit has occupied the niche among auditor services rather recently. In the western countries, its evolution contains several decades. In Russia, we started talking about ecological audit in the 1990. Thus, ecological audit is a new acquisition of the modern civilization.

While in the western countries there is already a theoretical and practical experience of its application, Russia just begins to introduce many of them. During this process the lack of a regulatory framework, the shortage of techniques and lack of practice, acute shortage of information, literature and research on these matters are noticed. In such circumstances this work can be considered as the attempt to fill the shortage.

Throughout the centuries scientists considered the matters of interaction of humans and the nature $[1,2]$. At the beginning of the 19th century the German thinker Friedrich Schelling brought the idea of the development in understanding of the nature and created his "nature philosophy". In 1866 other German scientist Ernst Gekkel entered the term "ecology" (from the Greek words oikos - "dwelling" and logos - "doctrine"). Gekkel's views

\footnotetext{
* Corresponding author: angela-1309.m@yandex.ru
} 
combined the views of Darwinism and the idea of pantheism, i.e. the identification of divine and natural beginnings. He suggested to replace the official religion with the belief in Nature. The huge contribution to the development of ecological views was made by V.I. Vernadsky, who in fact created the doctrine on the noosphere, which had been put forward in general by the French thinker Tellar de Chardenom. Vernadsky analysed the process of transformation of the biosphere to the noosphere as the area of the planet, captured by reasonable activity proceeding from needs of the human.

During the developing of the Provisions, concerning ecological audit, Goskomecology of Russia was guided by the ISO standards - 14000 [3, 4, 5, 6, 7]. Studying of this type of activity is complicated by almost total absence of the relevant literature. The most of publications are collections of the conferences reports, or separate articles in scientific periodicals. In this regard it is necessary to mention Makarov S.V., Shagarova L.B., Serov G.P., Shneydman's researches and some scientific developments which are carried out by Research Center Ecosafety (Ecobezopasnost).

Within ecological audit there is a problem, which is indissolubly connected with it; that is the assessment of the economic damage from ecological violations. In this regard it is necessary to mention the "Technique of determination of the prevented ecological damage on separate by views of environments and to the main activities of territorial nature protection authorities", developed by Goskomecology in the Russian Federation. At the same time, the comprehensive analysis of the compliance of payments for pollution over the maximum allowable concentration to the caused economic damage was not carried out so far. The matter of the assessment of environmental risks, which can appear during the assessment by auditors of nature, protection actions are developed in the West better than in Russia. Thus it is necessary to mention the risk assessment methodology, accepted to the USA and also the technique of carrying out ecological audit developed by the European Bank for Reconstruction and Development which part is devoted to the assessment of environmental risks. It is necessary to mention Avaliani C.JL's works, A.A., Strukova E.B., Shaposhnikov D.A., Gracheva M.V., etc. among the works published in Russia [8,9].

\section{Materials and Methods}

The complexity of modern environmental problems causes the necessity of application of auditor approach to their research. In turn there are three approaches to ecological audit (Figure 1) [9].

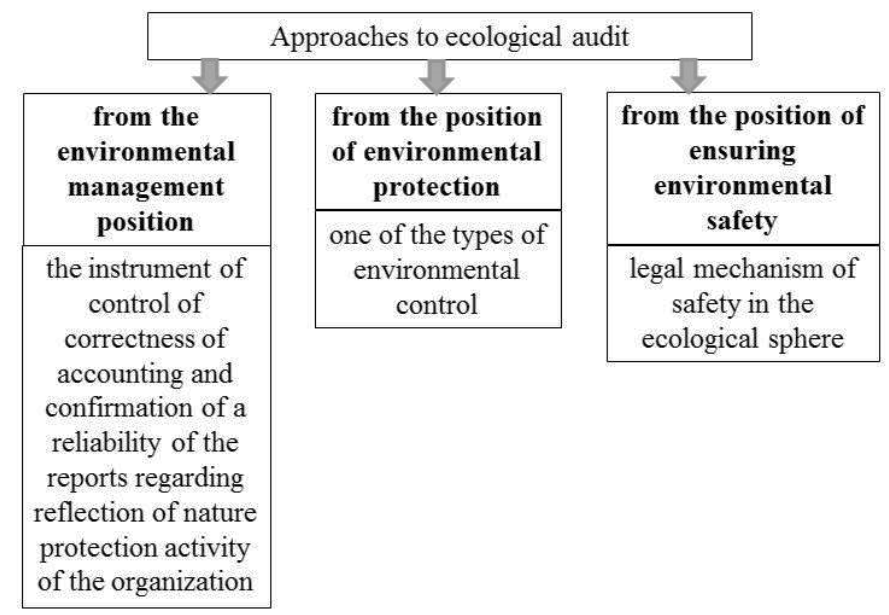

Fig. 1. Approaches to ecological audit. 
The system of ecological audit is very complex (Figure 2).

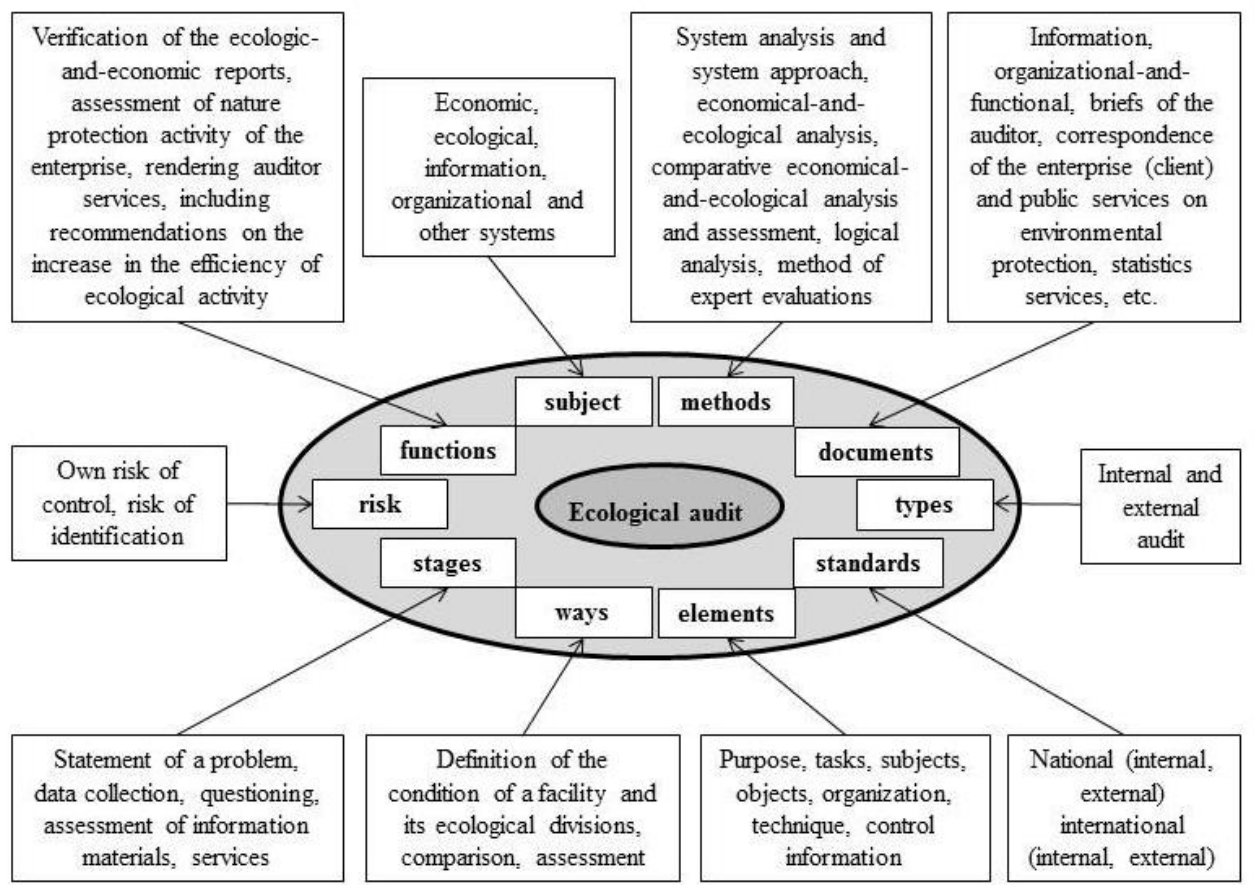

Fig. 2. Scheme of ecological audit.

Nowadays, the activity in the sphere of ecological audit keeps continuity with the achievements of domestic ecological science. Ecological audit as an independent non-state type of monitoring and analysis is aimed to make the adjective "reasonable" the keyword in the characteristic of humans' activity. The matters, connected with the ecological perspective, are mentioned at the different levels, from laboratories of the enterprises and educational audiences to political parties and global organizations.

\section{Results}

The analysis of a situation proves that many domestic enterprises intensified their actions according to the compliance of the ecological characteristics to regulatory requirements, first of all, concerning the observance of standards of direct and/or indirect impact on the environment, threshold limit values of pollutants and noise levels, radiation, vibration, etc. and also requirements to the technological processes and products or the performed works. The analysis of compliance of activity of an economic subject to the aforesaid criteria is one of the main directions of ecological work of auditors. It is necessary to emphasize that research are usually conducted not only proceeding from "the instant picture" of today's situation, but also in terms of the forecast of development of business of the enterprise and its further compliance to standardly legal acts reflecting state policy in the sphere of ecology.

Other directions of ecological audit include:

- development and/or correction of ecological strategy of an economic entity;

- assistance in planning of nature protection activity of the client; 
- carrying out the analysis of the actual familiarity and daily implementation of the regular procedures connected with ensuring ecological compliance of activity of an economic entity;

- consultation on issues of the increase in the efficiency of the use of natural resources;

- identification of reserves for the financial optimization of the ecological payments;

- carrying out special courses for the employees of an economic entity;

- consultation for the purpose of rationalization and improvement of environmental monitoring within the activity of economic entity; identification strong and weaknesses and also unused opportunities, concerning control of the ecological aspects of functioning of an economic entity;

- analysis of the degree of environmental safety of technological processes (including safety for personnel of the client); issue of recommendations on the minimization of harmful influencing factors;

- identification of the causes for irregular situations.

The last item needs to be considered in more detail. View of the auditor often allows defining which technological mistakes are the investigation of the established orders, insufficient readiness of personnel or lack of an operative communication with competent experts. Practice proves, that the employees of the enterprises often get used to these or those deviations (as they are frequent and in most cases do not lead to any accidents). Even the motivation to timely actions for restoration of the normal mode of the equipment, which is absent, is the result of such situation, thus the technological process is carried out in dangerous conditions for a long time. In many cases only an independent auditor and his or her assessment allow to raise attention level to the environmental matters $[10,11]$.

Ecological audit can also render the assistance during the solution of more major problems at the regional and federal levels. The prospects of application auditors are connected with the need for:

- the analysis of rationality of placement of the industrial enterprises in the region and determination of their structure from the ecologists' opinion on the safety in the conditions of the increasing scale and concentration of production;

- studying of the interference of the enterprises in a certain territory, taking into account the condition of power, transport communications, financial position of the key enterprises in the region, the situation in the household sphere and other factors;

- creation of an integrated approach to safety of the concrete region, taking into account the cumulative impact of human activity on the environment;

- carrying out the analysis of statistical data on the emergency situations and accidents in the regions and at the federal level;

- development of the concept of ecological retraining of personnel for the regional and federal structures;

- creations and implementation of the strategic concept directed to informing the public on importance of the solution of problems of ensuring environmental safety

- etc.

The interest of the public in environmental matters became more active in connection with the extensive discussion of some interstate agreements, which affect the aspects of national ecological wellbeing $[12,13]$.

Ecological audit is able to play an important role in the context of the international cooperation.

The international cooperation in relation to environmental problems needs the independent examination. In this regard broad attraction to carrying out preliminary estimate of the international agreements of domestic-owned auditor firms would promote the anticipation of many nature protection problems. 
It is important and difficult to coordinate national interests and global projects. For example, any state does not want to become a dump of radioactive waste from more prosperous countries during the international division of labour and the translation of productions. And only environmental professionals can fully estimate such a danger.

Elements of the ecological analysis are available in the financial audit too.

In some cases ecological influence turns out to be so considerable, that auditors are forced to study some aspects of nature protection. Examples of such circumstances can be:

- financial consequences of non-compliance of nature protection laws and regulations by the audited enterprise;

- presence at economic entity of legal obligations or its intention on a voluntary basis to make the essential expenses, directed to minimization or mitigation of consequences of harmful effects of its activity on the environment;

- the existence of the checked enterprise of the non-standard and (or) rare operations caused by attempts to solve these or those nature protection problems;

- application of some difficult estimated values, connected with the environmental matters (it is usually difficult to make an objective check of such figures, because of insufficiency of the statistical base and retrospective specific data for the comparison to the current estimates);

- the essential environmental risk, caused by the branch accessory of an economic entity or its specific features, which can cause the emergence of lawful claims, concerning compensation of damage, by the consumers of its products or by the population, living near it;

- high probability of the emergence of extraordinary ecological obligations, burdensome for enterprise [14].

\section{Discussion}

Ecological audit is undoubtedly useful.

But there is another extreme, which is ecological extremism. Its adherents urge to refuse many benefits of modern civilization, focusing on the ecological perspective, even to the detriment of requirements of the economy's development. At the same time, the information on the decrease in harmful emissions in some Russian regions due to decline of productivity is presented as positive. However it is not that case when "there's no evil without good". Any specialist, who loses his or her job, will not be able to welcome such option of improvement of the environment. It is necessary to find a "golden mean" in this matter. Search of a compromise between the interests of economic and scientifically technical progress and the requirements of environmental safety makes one of the spheres of application of forces of domestic auditors. The application of the system auditor approach can provide an effective search of optimal solutions of complex nature protection problems at the different levels, from service of the concrete enterprise before carrying out regional research and participation in elaboration of national environmental policy and preparation of interstate agreements [15-17].

\section{Conclusions}

Ecological audit can:

- give the objective assessment of the ecological condition of the enterprise, region, industry; 
- define the existing aberrations from the requirements of the current legislation and normative documents in the field of environmental protection or from the international standards;

- recommend some actions for carrying out the production activity of the enterprise in compliance with the requirements.

However, in spite of the fact that the trend of activation of legislative activities for environmental issues has outlined in Russia recently, the legislation remains undeveloped.

The adopted laws have serious defects: abundance of declarative provisions; weak regulation of the procedures. Problems which are solved within ecological audit are difficult and demand various vocational training of the auditors. The difficulty is that it is necessary to understand such a difficult object which the modern industrial enterprise is, to assess a situation adequately and make the corresponding recommendations for a short term. The special attention is deserved by the matters of the auditors' ethics as the data, obtained during the audit are confidential and cannot be disclosed without the consent of the customer.

\section{References}

1. T.H. Tietenberg, Environmental economics and policy (HarperCollins College Publishers, New York, 1994)

2. T.H. Tietenberg, Environmental and natural Resources Economics (HarperCollins College Publishers, New York, 1996)

3. International Standard ISO 14001:1996

4. International Standard ISO 14004:1996

5. International Standard ISO 14010:1996

6. International Standard ISO 14011:1996

7. International Standard ISO 14012:1996

8. T. Ermatov, F. Ilhomzhonova, International Journal of Humanities and Natural Sciences 6(1), 15-18 (2018)

9. E. Chibisova, Journal of International Scientific Publications: Economy \& Business 5(2), 600 (2015)

10. A. Mottaeva, MATEC Web of Conference 193, 01022 (2018)

11. E. Vasilyeva, MATEC Web of Conference 193, 01025 (2018)

12. A. Mottaeva, A. Zheltenkov, MATEC Web of Conference 170, 01045 (2018)

13. M.A. Bahauovana, M.A. Bahauovana, International Journal of Applied Engineering Research 11(9), 6808-6816 (2016)

14. S. Head, N. Horn, Essentials of Risk Management (Insurance Institute of America, USA, 2011)

15. R.K. Turner, D. Pearce, I. Bateman, Environmental Economics (Harvester Wheatsheaf, London, 1994)

16. R.K. O'Turner, D. Pearce, Economics of natural resources and the environment (Harvester Wheatsheaf, London, 1990)

17. S. Rinaldi, A Flammini, M. Pasetti, L. C. Tagliabue, A. C. Ciribini, S. Zanoni, 2018 IEEE International Instrumentation and Measurement Technology Conference (I2MTC), 14-17 May 2018, Houston, Texas, USA (2018). DOI: 10.1109/I2MTC.2018.8409740 